\title{
Preliminary Analysis of Spatial Ability Improvement within an Engineering Mechanics Course: Statics
}

\section{Steven David Wood, Utah State University - Engineering Education}

Steven Wood is a junior in the Civil Engineering program. After finishing his BS he plans on completing a MS in Civil Engineering. In addition to studies, he is a teacher's assistant and he teaches a recitation class for the Statics course. His Interests in the field of engineering are public transportation, specifically in rapid and heavy rail systems. His research interests include spatial ability, learning styles, and gender differences in meta-cognition.

\section{Dr. Wade H Goodridge, Utah State University}

Wade Goodridge, Assistant Professor in the Department of Engineering and Technology Education at Utah State University, has taught Solid Modeling, CAD, Introductory Electronics, Surveying, Statics, teaching and Learning, Assessment and Evaluation, and Introductory Engineering courses at Utah State University. Goodridge has been teaching for the Utah State College of Engineering for more than 15 years. He holds dual B.S degrees in industrial technology education and civil engineering from Utah State University, as well as an M.S. and Ph.D. in civil engineering from Utah State University. His research interests include spatial thinking/spatial ability at a course specific level in engineering, conceptual and procedural knowledge interplay in novice engineering students, and entrepreneurship.

\section{Mr. Benjamin James Call, Utah State University - Engineering Education}

Benjamin Call graduated with his Masters of Science degree in Mechanical Engineering (Aerospace Emphasis) in 2006 from Utah State University. After eight years with NAVAIR, he has returned to pursue a $\mathrm{PhD}$ in Engineering Education. He is funded by the Presidential Doctoral Research Fellowship. His research interests range from sophomore-level engineering curricula to spatial ability and creativity to student entrepreneurship.

Thayne L Sweeten Ph.D., Department of Biology, Utah State University,

Thayne Sweeten earned a Ph.D. in Medical Neurobiology and Indiana University - Purdue University at Indianapolis. He teaches biology courses for Utah State University and publishes research in pedagogy and the etiology of autism and related disorders focusing on immune mechanisms. 


\title{
Preliminary Analysis of Spatial Ability Improvement within an Engineering Mechanics Course: Statics
}

\begin{abstract}
Spatial ability has been an area of research for decades. Distinct correlations have been discovered regarding research into spatial ability and Science, Technology, Engineering, and Mathematics disciplines (STEM). However, spatial ability is a term that can be confusing to practitioners. For this purpose, spatial ability, a measure of an individual's capability to exercise a specific construct of spatial thinking, will be defined explicitly in this paper. Spatial ability has been positively correlated to success in the professional engineering world as well as within engineering coursework. In view of this correlational evidence, an argument forms for the academy to develop a more refined understanding of the improvement in spatial ability and underlying impacting mechanisms of spatial thinking within undergraduate engineering courses.
\end{abstract}

This paper presents preliminary research into spatial ability's correlation to performance in an engineering Statics course. Statics is a fertile engineering course to research as it is a gateway course where students often determine if they will persevere in engineering. It is the first class in the Engineering Mechanics Series and is required by most mechanical, civil, environmental, biological, and aerospace engineering programs.

Results indicate that spatial ability does improve significantly in a Statics course for both sexes. Data was collected using two spatial instruments, the Mental Cutting Test and the Purdue Spatial Visualization Test: Visualization of Rotations, and a demographic survey. A pre- and post-test design was used for both tests where tests where given in the first week and in the final week of the course. A series of paired t-tests are used to statistically analyze for improvement and the potential correlation between the spatial pre- and post-tests demographic variables. Additionally, the study was replicated in an Anatomy class to address potential risks to the study. Results indicate that spatial ability of the students in the Anatomy class does not significantly improve. Further research is suggested in looking into the demographic factors of each study including previous and concurrent course experience.

\section{Introduction and Literature Review}

Numerous studies have reported significant correlation of spatial thinking (the ability to use spatial skills in their learning and work) to success in performance, professional work $^{1,2}$, and within academic studies ${ }^{1,3}$. In addition to this, studies also show that spatial thinking is highly correlated to success in the engineering field specifically ${ }^{1}$. It has been recorded that entering engineering students have a significantly higher spatial ability than their colleagues in other fields of study ${ }^{1}$. Within the engineering field, those with higher spatial ability perform, on average, better than other students in the same field of engineering who have lower spatial ability $^{1,3}$. This better performance in their academic career then translates to their professional career $^{1,2}$. Terms such as spatial thinking, spatial cognition, and visuospatial thinking, in addition to spatial ability, are commonly used to discuss individuals' spatial understanding of innately 
spatial topics. For this paper's purposes, the term spatial ability will be used and defined as the measure of an individual's spatial aptitude.

In 1993, Sheryl A. Sorby conducted an experiment at Michigan Tech regarding spatial ability and engineering students. The experiment required all freshmen engineers to take a spatial ability test known as the Purdue Spatial Visualization Test: Visualization of Rotations (PSVT:R). That year, 535 students took the test and 96 (18\%) failed the test with a $60 \%$ or lower. From this group of 96 participants, 24 were randomly selected to take part in a three credit course that was developed to help the improvement of spatial ability. The remaining 72 students were not enrolled to serve as the control group ${ }^{3}$. At the end of the course, the 24 students were given the PSVT:R again to assess gain. The average of the test for the 24 students before the class was $51.7 \%$. After the class, their reported average had increased from $30.3 \%$ to $82.0 \%$. Additionally, the data indicated that males performed higher, on average, than females on the spatial ability test. Of those that took the test, $17 \%$ were female. Yet, of those that failed the test, nearly half were female $^{3}$. Even though males, on average, have higher initial spatial ability regarding rotations $^{2,4}$, Sorby's work demonstrates that spatial ability can be learned. It also demonstrates that the disparity in scores seen by the two sexes can be decreased or eliminated with training ${ }^{1}$.

The study continued for the next five years. A change in methods involved actively advising those who failed the pre-test to enroll into a spatial intervention course rather than continuing to randomly select participants for the spatial intervention as was done before. The students that were accepted and voluntarily took the spatial ability class demonstrated roughly the same percentage increase as did the randomly selected group the year prior. Continued data collection revealed an average student gain of $27 \%$ on their PSVT:R test results ${ }^{3}$. While some may extend this research to discover how much spatial ability improves in those who already have a higher level initially, the work conducted nevertheless shows that spatial ability is not innate and responds to training and experiences within the studied demographics.

It has also been verified that spatial ability can be learned through coursework not directly targeting its improvement ${ }^{2,5}$. In a study performed by Prieto and Velasco, it was desired to know if spatial ability could be improved through a course that focused on technical drawing. The study concluded that spatial ability does improve, and the improvement was similar in men and women $^{2}$. A similar study done by Németh focused on the development of spatial ability throughout a course focused on descriptive geometry. In her results, she reported that, indeed, spatial ability was improved by the end of the course but that males showed greater improvement in spatial ability than females ${ }^{5}$. Both studies agreed that spatial ability can be improved during engineering-related coursework; however, the two studies do not agree if males and females improved similarly or not. Finally, Sorby's text ${ }^{6}$, targeted to improve student's spatial ability, presents a method of increasing this ability using very traditional drafting instructional techniques. Her work provides one practical avenue to students to increase their spatial ability.

There has been much work done with respect to differences in spatial ability between sexes. Levine states that at as early as four years of age there is already a difference in spatial ability favoring males ${ }^{7}$. In a study done by Lippa, Collaer, and Peters, it was found that across 53 separate countries males performed higher than women on two separate spatial tests. Also, it was reported that gender equality and economic development were significantly associated with a higher performance on the two tests ${ }^{4}$. 
On December $10^{\text {th }} 2012$, 44 spatially minded researchers and administrators from education and industry met to discuss the placement of curriculum, based on spatial thinking, in higher education. They brought together their knowledge about the teaching and development of spatial thinking in order to find the most effective way to teach this skill to the next generation of engineers and to other students in visually intensive majors ${ }^{8}$.

On teaching spatial ability they reported the following:

Although we believe that current attempts to teach spatial thinking are effective, we have little objective evidence for this and are not currently in a position to advocate a best approach or set of approaches for teaching spatial thinking across the college curriculum. ${ }^{8}$

Even with this and other research, Sorby claims, "That it is still too early to determine if those with spatial abilities are simply attracted to engineering fields or whether engineering education and practice aid in the growth of spatial abilities ${ }^{1}$." Nevertheless, the argument is proposed that initial work is required to discover courses that are significantly spatial in nature ${ }^{9}$. Recently Uttal made this comment:

Having good spatial skills strongly predicts achievement and attainment in science, technology, engineering, and mathematics fields ${ }^{10}{ }^{11}$. Improving spatial skills is therefore of both theoretical and practical importance. ${ }^{12}$

In order to meet the demands of the world's engineering needs in the coming years, we need to address the deficit in engineering graduates ${ }^{13}$. Spatial interventions stand to impact STEM education as evidenced in Uttal's statement concerning the advantages for investigating spatial thinking,

Considered together, the results suggest that spatially enriched education could pay substantial dividends in increasing participation in mathematics, science, and engineering. ${ }^{12}$

As supported by previous research, fostering the development of student's spatial ability is one potential technique that may increase engineering student success. In accordance with the call for action made by Uttal ${ }^{12}$, spatially enhanced curriculum can and should be created and adopted into existing courses. However, we must first identify highly spatial topics and discover how students spatially reason through the concepts and problems taught within them to strategically tackle spatial enhancements that will have impacts. Research focused on such knowledge will set a foundation for instructors to develop spatially enhanced curriculum and will reveal if spatial ability can impact success at a course-specific level.

\section{Methods}

Data was collected as a convenience sample from two separate classes, Statics and Anatomy. The Anatomy class served as a reference group that did not receive the Statics course curriculum: the specific treatment for this study. The addition of the Anatomy class to this quasiexperimental study was implemented to address potential risks to the study discussed in detail later in this paper. 
Both the Statics and the Anatomy courses lasted 15 weeks, beginning in the end of August and ending in the first part of December. The two classes took the pre-tests for both the Mental Cutting Test (MCT) ${ }^{14}$ and the PSVT: $\mathrm{R}^{15}$ at the beginning of the course. This established initial spatial ability levels. These instruments have been used extensively in previous spatial ability assessment $^{1,5}$. At the end of the 15 week period, all the students then took the post-tests for the MCT and the PSVT:R to ascertain final spatial ability levels. A demographic survey was given at the beginning of the 15 week period on a volunteer basis.

The spatial instruments, both the MCT and the PSVT:R, were given online in a controlled testing environment. Each test was limited to 20 minutes $^{16-18}$ and the participants took the tests in groups of size ranging between 20 and 30. The tests were taken in computer labs with proctors present. For those participants requesting isolated testing environments, a single room and proctor was provided. The demographic survey given focused on past/current hobbies and experiences of the participants, sex, and major. Institutional Review Board (IRB) approval for the study was secured prior to data collection.

Risks to the study and participants are always of concern in engineering education studies. Measures were taken to help minimize and eliminate the risks to the study. Included below is a list of several risks and strategies used to address that particular risk.

Maturation: It is possible that improvement in spatial ability could have come from the continual maturation of the participants' minds. The study spans 15 weeks which is enough time for potential maturation of the mind to effect spatial ability. Anatomy results refute this effect as spatial ability was not seen to significantly increase in this class.

Testing: With identical pre- and post-tests there is the chance that the participants performed better on the post-test because they recalled previous answers. Literature indicates that a month is sufficient time to avoid most pre- and post-testing validity issues ${ }^{19}$. This research endeavor exceeded this recommended time allowance by nearly two and a half months.

Experimental Mortality: With two separated data collection times using the same instrument offered in pre- and post-test form, there was a possibility of an experimental mortality rate. For this work, participants who took only one of the pre- or post-tests were omitted from the data set. This is considered to be an acceptable risk as the sample size was large enough to still be significant with omitted results.

\section{Instrument Design}

In order to collect the data, two separate spatial instruments were used: the MCT and the PSVT:R. These two instruments were chosen to better target spatial ability of the individual students as both measure different constructs of this intelligence. Both instruments were originally occupationally designed ${ }^{11,20}$ and have been proven to be valid and reliable ${ }^{21,22}$. Students were allowed 20 minutes to take each test ${ }^{22-24}$, and the MCT contains 25 questions while the PSVT:R contains 30 questions. 
The MCT was developed to test cut-surface recognition. The MCT looks to assess participants' capability to mentally model the intersection of a cutting plane and three dimensional object. Each question presents a two-dimensional image of a three-dimensional object that has a plane drawn through the object. The participant is to select, out of five possibilities, what the crosssection would look like if the object was cut along the given plane and the cut plane was rotated to face the student. For the PSVT:R, each question begins with a two-dimensional image of a three-dimensional object. It then gives an image of the same object after it has been rotated in a specific fashion. The participant is then shown another image of a three-dimensional object and is asked to rotate it in the same manner as the first object. The answer is then selected out of five images that are possible solutions, but only one of which is correct. An example question from each test is given here. The MCT question is presented first in Figure 1 and the PSVT:R is presented next in Figure 2.

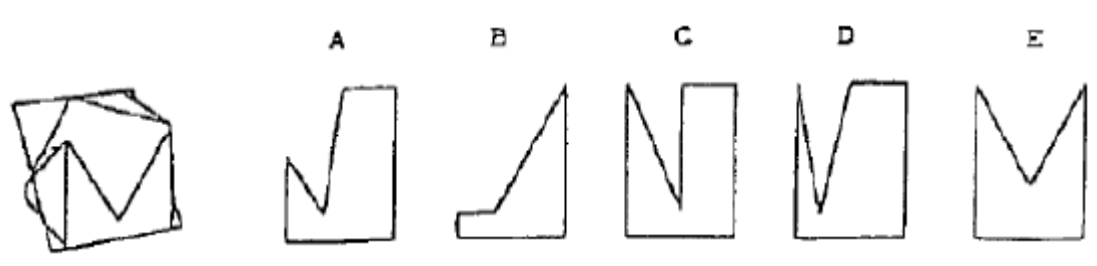

Figure 1: Example problem from the MCT.
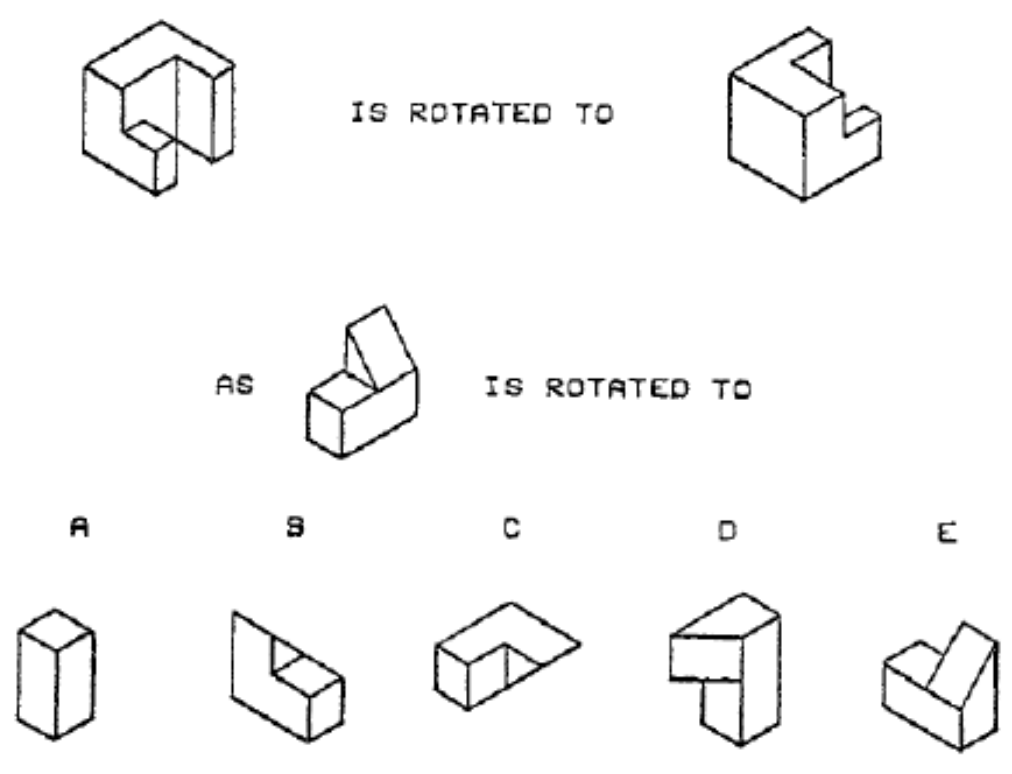

Figure 2: Example problem from the PSVT:R (copyright, Purdue Research Foundation, 1976, used with permission)

A demographic survey targeting hobbies and previous experience, sex, and major was developed and given to students near the beginning of the study. It was composed of 33 questions. The instrument was delivered through Qualtrics ${ }^{\mathrm{TM}}$ and students were allowed to voluntarily take the instrument. 


\section{Data Collection}

In total, 182 students participated in the study. Five students did not complete all four spatial instruments (MCT and PSVT:R pre- and post-) and were omitted from the study. With these omissions there were then 94 viable participants in the Anatomy class, with 25 males and 69 females, and 83 viable participants in the Statics class, with 73 males and 10 females. Overall, 728 pre- and post-tests for both instruments were administered electronically and 708 were used in the study. Out of the 83 viable Static participants, 53 of them completed the demographic survey that was given.

\section{Results}

All data was analyzed using paired t-testing to find any significant gain between average preand post-spatial test scores. First, Statics data was compared with the Anatomy data to find if spatial ability improved within the two separate classes. Males and females were compared only within the Statics class as Anatomy results showed no significant improvement of spatial ability. In addition to males and females, a selected number of past experiences from the demographic survey were also analyzed to find any correlation between experience and spatial ability gain.

Upon preliminary graphical analysis, one outlier was identified and removed. After omitting this outlier, the sample size for the study was 176 students total with 94 in the Anatomy class, 25 males and 69 females, and 82 in the Statics class, 72 males and 10 females. The mean test scores with their accompanying standard deviations for each class are presented in Table 1.

Table 1: Mean spatial test scores for both classes with respective standard deviations

\begin{tabular}{|l|l|l|l|}
\hline Anatomy & & Mean & SD \\
\hline & Pre-MCT & 7.766 & 3.3293 \\
\hline & Post-MCT & 8.128 & 3.5416 \\
\hline & Pre-PSVT:R & 16.053 & 5.9467 \\
\hline Statics & Post-PSVT:R & 16.383 & 6.1331 \\
\hline & & & \\
\hline & Pre-MCT & 13.939 & 5.2242 \\
\hline & Post-MCT & 16.537 & 4.6778 \\
\hline & Pre-PSVT:R & 24.268 & 4.2631 \\
\hline & Post-PSVT:R & 25.256 & 4.2537 \\
\hline
\end{tabular}


Using paired t-tests, Anatomy showed no significant gain in pre- and post-testing. Statics showed significant improvement on both tests: MCT t (82) $=6.338, \mathrm{p}<0.001$, and PSVT:R t (82) = 2.593, $\mathrm{p}=0.011$. On average, the Statics students improved 2.598 (SD: 3.7114) points on the MCT and .988 (SD: 3.4516) points on the PSVT:R.

Other courses that Statics students are concurrently enrolled in at this University are as follows: Introduction to Computer Programming, Organic Chemistry, Intermediate Writing, Computer Aided Drafting, Linear Algebra and Differential Equations, Geology/Geography, Multivariable Calculus, Electronics, Physics II, Properties of Biomaterials, and a general breadth course. This is based on the typical schedule students are advised to follow. This concurrent course enrollment spans the four typical majors present in class: Environmental, Civil, Biological, and Mechanical/Aerospace Engineering. Each course is presented in Table 2 along with the percentage of Statics students in each class and an assigned expected impact factor. The courses were preliminarily evaluated with a Likert scale ranging from "not at all”, "small degree”, "moderate degree”, "high degree”, and "very high degree” by three experts in these courses” content. Consideration was directed to the prevalence of spatially-related tasks within the curriculum. Breadth classes include History, Philosophy, Folklore, Ethics, Communication, and Literature courses which are considered to be limited in spatial impact. Creative arts, another class in the general breadth area, may have a higher spatial impact; however, treating the entire set of breadth courses as a single unit decreases the likelihood of spatial ability impact.

Table 2: Expected concurrent courses, percentage of Statics students in each course, and associated impact factor

\begin{tabular}{|l|c|c|}
\hline \multicolumn{1}{|c|}{ Class } & $\begin{array}{c}\text { Percentage of Statics } \\
\text { Students }\end{array}$ & $\begin{array}{c}\text { Expected Impact Factor for } \\
\text { Spatial Ability }\end{array}$ \\
\hline Intro to Computer Programming & $20.76 \%$ & Small Degree \\
\hline Organic Chemistry & $1.89 \%$ & High Degree \\
\hline Intermediate Writing & $100 \%$ & High Degree \\
\hline Computer Aided Drafting & $11.23 \%$ & Small Degree \\
\hline Linear Algebra \& Diff Eq. & $1.89 \%$ & Moderate Degree \\
\hline Geology/Geography & $18.87 \%$ & Small Degree \\
\hline Electronics & $79.24 \%$ & Moderate Degree \\
\hline Physics II & $69.81 \%$ & Small Degree \\
\hline Multivariable Calculus & $88.68 \%$ & Moderate Degree \\
\hline Properties of Biomaterials & $9.43 \%$ & \\
\hline
\end{tabular}




\begin{tabular}{|l|c|c|}
\hline General Breadth & $28.3 \%$ & Small Degree \\
\hline
\end{tabular}

Intermediate writing, with a "not at all" potential spatial ability impact, is scheduled to be taken by all students concurrently. This course is closely followed by Multivariable Calculus which is considered to have a "small degree" of potential spatial ability impact. Continued further research isolating the correlation of concurrent coursework with Statics and spatial ability is underway and recommended. This work presents a preliminary look into this area of spatial influence.

Although female representation in the Statics portion of the study was low at 10 out of 82 participants, a look into female spatial scores in comparison to males' scores opens avenues for continuing this line of research. Based on the pre-test scores, it was found that females improved, on average, 4 points on the MCT $(\mathrm{t}=3.422, \mathrm{p}<.001)$. Males' gain was not significantly different than the females' on this instrument. However, on the PSVT:R there was a difference between the sexes. Females improved by 3 points $(t=2.779, \mathrm{p}=.006)$, while males scored 2.292 points less than females $(\mathrm{t}=-2.004, \mathrm{p}=.048)$.

Data was also taken from the demographic surveys and correlated with the data from the MCT and the PSVT:R using t-tests. Previous experience in drafting, Legos, woodworking, and welding was investigated and will be discussed. Drafting was selected due to the fact that previous research has been conducted correlating improvement in spatial ability after completing a drafting course ${ }^{2}$. Legos, woodworking, and welding were selected as initial demographic points of interest that target vocational and a dominant childhood hobby that is usually gender specific. Experience was measured on a five point Likert scale where a 1 equates to "very little", 2 to "some", 3 to "moderate", 4 to "considerable", and 5 to "immersed." Values of 1-3 were treated as low or no experience and values 4-5 were treated as high experience. These four items are listed in Table: 3 with their associated average improvement, $t$ values, and $\mathrm{p}$ values.

Table 3: Demographic factors and their relationship to high and low spatial gain

\begin{tabular}{|c|c|c|c|c|c|}
\hline $\begin{array}{c}\text { Area of } \\
\text { Experience }\end{array}$ & $\begin{array}{c}\text { High/Low } \\
\text { Experience }\end{array}$ & $\begin{array}{c}\text { Spatial } \\
\text { Test }\end{array}$ & $\begin{array}{c}\text { Average } \\
\text { Improvement }\end{array}$ & T - Value & P - Value \\
\hline \hline \multirow{3}{*}{ Drafting } & Low & MCT & $\begin{array}{c}4.000 \\
\text { not significant }\end{array}$ & $\begin{array}{c}2.462 \\
\text { not significant }\end{array}$ & $\begin{array}{c}0.017 \\
\text { not significant }\end{array}$ \\
\cline { 2 - 6 } & Low & PSVT:R & 3.167 & 2.285 & 0.026 \\
& High & not significant & not significant & not significant \\
\hline \multirow{2}{*}{ Legos } & Low & MCT & $\begin{array}{c}3.027 \\
\text { not significant }\end{array}$ & not significant & not significant \\
\hline
\end{tabular}




\begin{tabular}{|c|c|c|c|c|c|}
\hline & $\begin{array}{l}\text { Low } \\
\text { High }\end{array}$ & PSVT:R & $\begin{array}{c}1.486 \\
\text { not significant }\end{array}$ & $\begin{array}{c}2.641 \\
\text { not significant }\end{array}$ & $\begin{array}{c}0.011 \\
\text { not significant }\end{array}$ \\
\hline \multirow{2}{*}{ Woodworking } & $\begin{array}{l}\text { Low } \\
\text { High }\end{array}$ & MCT & $\begin{array}{c}3.211 \\
\text { not significant }\end{array}$ & $\begin{array}{c}4.999 \\
\text { not significant }\end{array}$ & $\begin{array}{c}0.000 \\
\text { not significant }\end{array}$ \\
\hline & $\begin{array}{l}\text { Low } \\
\text { High }\end{array}$ & PSVT:R & $\begin{array}{l}\text { not significant } \\
\text { not significant }\end{array}$ & $\begin{array}{l}\text { not significant } \\
\text { not significant }\end{array}$ & $\begin{array}{l}\text { not significant } \\
\text { not significant }\end{array}$ \\
\hline \multirow{2}{*}{ Welding } & $\begin{array}{l}\text { Low } \\
\text { High }\end{array}$ & MCT & $\begin{array}{c}3.191 \\
\text { not significant }\end{array}$ & $\begin{array}{c}5.638 \\
\text { not significant }\end{array}$ & $\begin{array}{c}0.000 \\
\text { not significant }\end{array}$ \\
\hline & $\begin{array}{l}\text { Low } \\
\text { High }\end{array}$ & PSVT:R & $\begin{array}{c}1.021 \\
\text { not significant }\end{array}$ & $\begin{array}{c}2.017 \\
\text { not significant }\end{array}$ & $\begin{array}{c}0.049 \\
\text { not significant }\end{array}$ \\
\hline
\end{tabular}

\section{Discussion}

Statics students showed a significant gain in spatial ability while Anatomy students did not. In the Statics class, it was found that males had an initial higher spatial ability when compared to females, on average scoring 3.23 higher on the MCT and 5.77 higher on the PSVT:R. This confirms what has been previously reported by Sorby and other researchers ${ }^{1,3,7,25,26}$. Although males outperform females initially, females are not hindered in any way in their capability to improve in their spatial ability. In fact, females improved significantly more on the PSVT:R than their male counterparts, scoring an average 2.29 points higher than males. With recognition that the PSVT:R is measuring a rotational or orientation-type of spatial construct, this begs an investigation into what mechanisms found in a Statics curriculum accelerate this type of spatial ability improvement in women more than men. It is possible that the same final level of rotational spatial ability can be achieved despite individuals starting with different initial levels of spatial ability. It is also plausible that spatial ability improvement is not necessarily the same for different sexes given the same treatments. Additionally, the PSVT:R instrument may also be subject to a ceiling effect ${ }^{27}$ for this population.

The effects of past experiences may demonstrate evidence that spatial ability does not linearly improve for those progressing in this area from novice to more expert. Simply said, a greater duration and exposure to spatial experiences may be required for subsequent and significant spatial ability improvement in those who initially start with higher spatial ability. Results reveal that those with greater involvement in drafting, Legos, woodworking, and welding did not improve in spatial ability as much as those with lower involvement. This trend was observed in all areas except the results correlated to woodworking and the gain on the PSVT:R. Results also 
indicate that those with limited experience, scores of 1-3 on the demographic survey, showed no significant improvement. It is also possible that these demographic areas have already delivered a spatial enhancement mechanism that was as useful as any mechanism for improvement that may be delivered in the Statics curriculum. Further analysis of the demographic data is now underway.

The ability to rotate and understand an object's orientation in three-dimensional space is suspected to be correlated with the mental rotation requirement present in the PSVT:R. A prime example in Statics is understanding the decomposition of a force into its basic components, which requires orientation in two- or three-dimensional space so that appropriate analysis methods may be employed. Generally, the analytical methods involve trigonometry which is a mathematical concept. But as stated by Call, Goodridge, and Green, the ability to use trigonometry "is based on the assumption that through visualization (a conceptual process), students can identify proper application of trigonometric functions ${ }^{28}$." They also continue to state that errors in problems containing two and three dimensional vectors come from a misunderstanding of a spatial nature, rather than an error in using a trigonometric function, such as plugging in the wrong angles. Hegarty and Kozhevnikov also states the following:

There is extensive research in mathematics showing a correlation between spatial ability and mathematical performance. . . For example, Sherman ${ }^{29}$ reported that the spatial ability factor was one of the main factors significantly affecting mathematical performance. This correlation increases with the complexity of mathematical tasks ${ }^{30}$.

In addition to orientation, proportionality, a construct proposed to be evident in some MCT problems, is also suspected to be correlated to understanding engineering concepts of equilibrium. In Statics, an example is the mental model of force interactions where defining analytical equations of equilibrium relies on the ability to recognize and balance force magnitudes. Another example in Statics of proportion is found in the analysis of friction forces. Once a force opposing friction becomes equal to that friction force, the object is on the verge of movement. With such problems, understanding proportionality (of magnitudes) becomes extremely relevant.

It is advantageous to locate topics that are highly spatial in nature within Statics. Typical course topics found in Statics texts and curricula include General Principles, Force Vectors, Equilibrium of a Particle, Force System Resultants, Equilibrium of a Rigid Body, Structural Analysis, Internal Forces, Friction, Center of Gravity and Centroid, and Moments of Inertia ${ }^{31}$. Preliminary qualitative analysis, ranking subtopics within these subject areas by three experts in the curriculum and on a Likert scale ranging from "not at all”, "small degree", "moderate degree", "high degree", and "very high degree" indicates a proposed emphasis of spatial ability. The four highest perceived spatial impacting areas, arranged in decreasing spatial order, found in the Statics curriculum are: Friction, Internal Forces, Center of Gravity and Centroid, and Force System Resultants. 
Statics students improved significantly more than their Anatomy counterparts on both tests. This differential in improvement gives supporting evidence that some mechanism students are exposed to in the semester they are taking Statics is significantly improving their spatial ability. With review of data and expert evaluation of other concurrent coursework, it is highly probable that this increase in spatial ability is due to the Statics course curriculum alone.

\section{Recommendations for Future Work}

Results indicate the existence of a significant improvement during the semester students were engaged in Statics during the fall semester. This begins foundational work towards discovering engineering courses and topic areas within those courses that may be highly spatial in their content. With additional work, investigating the mechanisms of spatial thinking in engineering curricula, progress can then be made toward interventions that may have impacts on success and retention in engineering courses. Course-specific enhancements may prove to be an extremely viable means of addressing spatial thinking improvement in students. Further research on other previous coursework as well as concurrent coursework is warranted. Research should also be expanded into other fields of study, such as interior design, engineering technology, chemistry, and medical fields. Results associated with the demographic data also provide initial insight into the impacts experiences have on students' spatial ability before they enter collegiate-level classes.

\section{Limitations}

This study pilots a preliminary investigation into the effects that Statics curriculum may play on an individual's spatial ability. Demographic questions were focused on sex, major, and experiences/hobbies. Deeper statistical analysis is needed to determine the effect of other concurrent course on correlations with spatial ability.

The individuals that make up the sample are, for the majority, made up of one ethnic demographic. Due to the local dominant religion, the majority have the same set of values. The majority of the students were males, consisting of $87 \%$ of the sample. Most participants were middle class. It is desirable to continue collecting data, particularly for the purposes of increasing female representation and the associated sample size. This is important as $18 \%$ of engineering bachelor degrees are awarded to females and they form an underrepresented population within engineering majors.

\section{Conclusion}

There is a significant improvement in the students' spatial ability scores at the end of the Statics course. Some mechanism improving spatial ability is likely present in Statics curriculum. In contrast, there was no significant increase of the students' spatial ability scores throughout the Anatomy course. Additionally, and in accordance with Sorby's previous findings, 1, 2, 32 this work provides more evidence that spatial ability can be trained and improved. While males initially start at a higher initial spatial ability as measured with the MCT and PSVT:R than females, spatial ability gain is possible by both sexes. Spatial ability gain may not be linearly related to 
exposure to spatial experiences. Those with more expertise in spatial ability may require greater time investment to improve this ability than those starting at novice levels of spatial ability. With the results from this study, engineering educators can begin to develop insight into how spatial ability improves in an undergraduate engineering course. This work presents a model for investigating spatial ability in undergraduate engineering.

\section{Funding}

Funding for Steven Wood's contribution was provided by the College of Engineering at Utah State University (USU) via the Engineering Undergraduate Research Program. Benjamin Call's contribution was supported by USU's Presidential Doctoral Research Fellowship.

\section{References}

1. Sorby, S., B. Casey, N. Veurink and A. Dulaney (2013). "The role of spatial training in improving spatial and calculus performance in engineering students." Learning \& Individual

2. Prieto, G., \& Velasco, A. D. (2010). Does spatial visualization ability improve after studying technical drawing? Quality and Quantity: International Journal of Methodology, 44(1015), 1024

3. Sorby, S. A. (2009). "Educational Research in Developing 3-D Spatial Skills for Engineering Students." International Journal of Science Education 31(3): 459-480.

4. Lippa, R. A., Collaer, M. L., \& Peters, M. (2010). Sex differences in mental rotation and line angle judgments are positively associated with gender equality and economic development across 53 nations. Archives of Sexual Behavior, 39(4), 990-997.

5. Nemeth, B. (2007). Measurement of the development of spatial ability by mental cutting test. Annales Mathematicae et Informaticae, 34, 123-128.

6. Sorby, S. A., \& Wysocki, A. F. (2003). Introduction to 3D Spatial Visualization: an active approach. Cengage Learning.

7. Levine, S. C., Huttenlocher, J., Taylor, A., \& Langrock, A. (1999). Early sex differences in spatial skill. Developmental Psychology, 35(4), 940-949. http://dx.doi.org/10.1037/ 0012-1649.35.4.940.

8. Janelle, D. G., M. Hegarty and N. S. Newcombe (2014). "Spatial Thinking Across the College Curriculum: A Report on a Specialist Meeting." Spatial Cognition \& Computation: An Interdisciplinary Journal of Problem-based Learning 14: 124-141.

9. Goodridge, W. H. (2015, September). Undergraduate Engineering and its Connections to Spatial Thinking. In D. Uttal and R. Linsenmeier (Chair). Integrating Cognitive Science with Innovative Teaching in STEM Disciplines: Modeling and Spatial Learning in STEM. Lecture conducted from Northwestern University, Evanston IL.

10. Wai, J., D. Lubinski and C. P. Benbow (2009). "Spatial Ability for STEM Domains: Aligning Over 50 Years of Cumulative Psychological Knowledge Solidifies Its Importance." Journal of Educational Psychology 101(4): 817-835.

11. Shea, D. L., Lubinski, D., \& Benbow, C. P. (2001). Importance of assessing spatial ability in intellectually talented young adolescents: A 20-year longitudinal study. Journal of Educational Psychology, 93(3), 604-614. doi:10.1037/0022-0663.93.3.604

12. Uttal, D. H., N. G. Meadow, E. Tipton, L. L. Hand, A. R. Alden, C. Warren and N. S. Newcombe (2013). "The malleability of spatial skills: a meta-analysis of training studies." Psychological Bulletin 139(2): 252-402.

13. Olson, S., \& Riordan, D. G. (2012). Engage to Excel: Producing One Million Additional College Graduates with Degrees in Science, Technology, Engineering, and Mathematics. Report to the President. Executive Office of the President.

14. CEEB (1939). CEEB Special aptitude test in spatial relations. USA. 
15. Guay, R. (1976). Purdue spatial visualization test, Purdue University.

16. Gorska, R. and S. A. Sorby (2008). Testing instruments for the assessment of 3-D spatial skills. ASEE Annual Conference. Pittsburg, PA, ASEE.

17. Branoff, T. J. (2000). "Spatial Visualization Measurement: A Modification of the Purdue Spatial Visualization Test - Visualization of Rotations." Engineering Design Graphics Journal 64(2): 14-22.

18. Sorby, S. A., T. Drummer, K. Hungwe and P. Charlesorth (2005). Developing 3-D spatial visualization skills for non-engineering students. Proceedings of the 2005 American Society for Engineering Education Annual Conference \& Expossition, Portland, Oregon, American Society of Engineering Education.

19. Stangor, C. (2003). Research methods for the behaviorial sciences. Boston, MA., Houghton Mifflin Harcourt.

20. Hegarty, M. (2010). Components of Spatial Intelligence. San Diego, CA, Elsevier Inc.

21. Sorby, S. A. and B. J. Baartmans (2000). "The Development and Assessment of a Course for Enhancing the 3-D Spatial Visualization Skills of First Year Engineering Students." Journal of Engineering Education 89(3): 301-307.

22. Gorska, R. and S. A. Sorby (2008). Testing instruments for the assessment of 3-D spatial skills. ASEE Annual Conference. Pittsburg, PA, ASEE.

23. Branoff, T. J. (2000). "Spatial Visualization Measurement: A Modification of the Purdue Spatial Visualization Test - Visualization of Rotations." Engineering Design Graphics Journal 64(2): 14-22.

24. Sorby, S. A., T. Drummer, K. Hungwe and P. Charlesorth (2005). Developing 3-D spatial visualization skills for non-engineering students. Proceedings of the 2005 American Society for Engineering Education Annual Conference \& Expossition, Portland, Oregon, American Society of Engineering Education.

25. Linn, M.C., \& Petersen, A.C. (1985). Emergence and characterization of sex differences in spatial ability: A meta-analysis. Child Development, 56, 1479-1498.

26. Sorby, S. and N. L. Veurink (2012). Spatial ability among minority and international engineering students. 2012 Annual Conference of the American Society of Engineering Education, San Antonio, Texas, American Society of Engineering Education.

27. Call, B. J. and Goodridge, W.H. (2016). Spatial Ability Instrument Ceiling Effect and Implications, ASEE Annual Conference. New Orleans, LA, ASEE.

28. Call, B.J., Goodridge, W.H, Green, C. Strategy, Task Performance, and Behavioral Themes from Students Solving 2-D and 3-D Force Equilibrium Problems, ASEE National Conference, Seattle, WA, June 15, 2015.

29. Hegarty, M., Kozhevnikov, M. (1999). Types of Visual-Spatial Representations and Mathematical Problem Solving. "Journal of Educational Psychology 91(4): 684-689.

30. Sherman, J. A. (1979). Predicting mathematical performance in high school girls and boys. Journal of Educational Psychology, 71, 242-249.

31. Hibbeler, R.C. (2016). Engineering Mechanics Statics, San Francisco, Pearson Prentice Hall, $14^{\text {th }}$ Ed.

32. Sorby, S. (2005b). Impact of changes in course methodologies on improving spatial skills. International Journal for Geometry and Graphics, 9, 99-105. 